\title{
SERVICE INNOVATION: CONVERTING PARETO LOSS INTO REVENUE
}

\author{
Irene C L Ng ${ }^{1}$, Ph.D.
}

Forthcoming in the Journal of Revenue \& Pricing Management

Dr. Irene $\mathrm{C} \mathrm{L} \mathrm{Ng}$ is an Associate Professor of Marketing and the Director for the Centre for Service Research at the School of Business and Economics, University of Exeter (U.K.). Irene was previously the CEO of SA Tours, the largest tour operator in Southeast Asia based in Malaysia, Singapore and China and the founder and CEO of Empress Cruise Lines, a cruise company turning over USD250m per annum. Contact Information: School of Business and Economics, University of Exeter, Streatham Court, Rennes Drive, Exeter EX4 4PU, United Kingdom Tel: +44 (0) 1392 263250, Fax: +44 (0) 1392 263242, Email: Irene.Ng@exeter.ac.uk 


\section{INTRODUCTION}

Price is the only avenue through which a commercial enterprise is able to bring revenue to the firm, and is therefore critical to the firm's survival. Getting the price right means better profits, but getting it wrong could be disastrous as mistakes are not easily tolerated. Past literature has shown that revenue management success is dependent on firms with good pricing as well as segmentation strategies (Kimes, 1989, Ng, 2006).

It is often easy to think of pricing as merely a mechanism for higher revenue and to have with it, a rather detached view of how pricing strategies should be developed. Yet fundamentally, for the firm to get its pricing right, individual buyers must be willing to pay for the good or service. When discussing the individual buyer, there is a need to understand what influences the buyer's willingness to pay i.e. the maximum amount an individual is willing to pay for a product. It is commonly acknowledged that a buyer's inclination to purchase increases if there is a larger gap between his or her willingness to pay, and the costs he or she has to bear to obtain the product, such as price. This gap is what economists call the consumer surplus, and the rational buyer behaves in such a way that will maximise his or her surplus. This understanding is seriously in need of revision. Today, consumers' choices are not merely dependent on price, but on the value that they get from the purchase which has both price and non-price considerations.

Academic discussions on value can be condensed into an understanding of gross value and net value. Gross value is equivalent to expected benefits, while net value is expected benefits minus expected outlays (Lovelock and Wirtz, 2006). The higher the net value, the higher the probability of the buyer buying the product, because buyers expect that purchasing the product will make them better off than if they don't buy it. In other words, the higher the net value, the higher the "value for money."

To enjoy the benefits of a service, buyers are aware that they are required to pay a price. This price is the expected outlay by the buyer that would result in the buyer's computation of net value. Expected outlays include monetary and non-monetary costs. When monetary costs are discussed, one would automatically think of the price charged by the firm. However, there are often other monetary costs involved when a customer consumes a service. Signing up with a gym, for example, may require the buyer to buy gym gear or incur car park charges. Taking a train may mean a taxi ride to the station, while obtaining a degree means additional outlay for accommodation, food, and books.

Monetary costs are not the only costs incurred by the customer. In buying and consuming services, many buyers are often not aware of the non-monetary costs. Perhaps they may moan about the long queues at a restaurant, or even about the uncertainty of satisfaction ("Will I really learn tennis from this instructor?"), or balk at the idea of going to a dentist (the non-monetary cost of pain and discomfort). Yet such considerations are unconsciously processed, and the net value outcome may result in the decision of whether or not to purchase the service (see figure 1). 


\section{$<$ Figure 1 about here $>$}

Literature has provided various categories of non-monetary costs $(\mathrm{Ng}$, 2008, Lovelock and Wirtz, 2006). Time costs refer to the direct cost of time incurred when the buyer spends that time consuming the service. Aside from the direct time costs, the consumption of a service often requires sacrifices on the part of the buyer i.e. the opportunity costs. The cost of a golf game is not only the green fee or the cost of the time spent on the golf course, but also what the golfer could be doing during that time, which is always changing. Sensory costs refer to the physical discomfort which may be an outlay that many may find unacceptable and therefore they will decide not to purchase. Psychological costs such as fear or loss of control may deter buyers from consuming a service.

Seen in the light of expected benefits and outlay, the understanding of net value shows that price is over-rated as a reflection of the service's value or benefit to the buyer. The key strategic value for decision making is therefore net value; how the net value is affected by the expected benefits and outlays (price and non-price), and the construction of the pricing policy within such a framework.

Consequently, there is a need for a revised understanding of the key economics concepts relating to price. This revised understanding replaces consumer surplus with net value, and incorporates both price and non-price outlays into the expected outlay. The term 'willingness to pay' is only correct if price is the ONLY outlay (which is unlikely). Otherwise, the more accurate term should be 'willingness-to-outlay'. The revised understanding (see figure 2) provides a more complete understanding of buyers' choices and the role of price within that choice.

\section{$<$ Figure 2 about here $>$}

\section{PARETO LOSS}

An interesting insight falls out of the revised understanding. Non-monetary costs borne by buyers constitute what I term as pareto loss ( $\mathrm{Ng}, 2008)$. An allocation of resources is pareto optimal when there is no other allocation that can make at least one individual better off, without making any other individual worse off. Pareto loss, conversely, means that there are no gainers. In the case of an exchange where there is a willing buyer and a willing seller of the service, the non-monetary costs borne by the buyer does not benefit the buyer nor the seller. In other words, the firm does not profit from the non-monetary costs borne by the buyer as a result of buying or consuming the service, and neither does the customer. Waiting is a classic example. The firm does not benefit from customers waiting nor do customers like waiting. Waiting is therefore a pareto loss; neither party has anything to gain from it. As a matter of fact, having to wait may incur actual losses for some service firms, as some buyers may give up on buying the service. There may even be pressure on the price as buyers may demand 'compensation' for having to wait.

\section{SERVICE INNOVATION AND PARETO LOSS}


Being able to identify pareto loss in a firm's service offering provides the firm an opportunity to innovate by converting the pareto loss to higher revenue through increased price, increased demand or improved customer satisfaction.

Figure 3 shows two options (and their combinations) for higher revenue. The firm can attempt to reduce the customer's non-price outlay and increase the price accordingly, maintaining the total expected net value (ENV) and therefore retaining the number of customers in the market for the service. Examples include dry cleaning services, where customers willingly pay a higher price for an express (quicker) service, or removal services where companies offer packing and unpacking service for an additional charge.

Alternatively, the firm can benefit from an increase in demand by reducing the non-price outlay and not increasing the price of the service at all. By doing so, the ENV increases and this may entice more customers to purchase the service. For example, shoppers at IKEA are able to dine in a café and mothers can drop off their children at a well-designed and well-managed daycare with lots of activities for kids (Moon, 2004). The company recognised that there was value in reducing outlays of the shopping experience i.e. who would look after the children, what do we do for lunch, etc. IKEA also shows that providing better value does not always mean higher revenue by increasing price (IKEA positions itself as a discount retailer) but by increasing demand.

\section{< Figure 3 about here>}

Today, technology allows firms to convert pareto loss such as loss of time or a perception of risk into higher revenues for firms. Customers who have little time to go to the bank or the post office can now do their banking or bill payments online. No time to learn a language? Audio CDs that you play on the way to work every day allow you to practise Chinese/French/German. Want to check your emails on the go? Personal Digital Assistants (PDA) enable you to do just that. No time to plan dinner? Your 'intelligent' fridge is able to tell you what you have and suggest recipes. Reluctant to rent a car because you might get lost? The Satnav (satellite navigation) is there to help. And where it might be a hassle to go to the supermarket on weekends, you can now do your grocery shopping online at Tesco.com and have it delivered to your doorstep. When there is uncertainty as to whether there is enough snow at ski resorts, a webcam and a half-hour report on slope conditions available on the internet provides tremendous value to the skiing customer.

Even without technology, innovative entrepreneurs are able to identify the costs that many of us would gladly 'buy' our way out of. For example, providing leisure activities for non-golfers at a golf resort helps to ensure that non-golfing partners are taken care of while golfers enjoy their rounds on the course. It is also possible to hire a personal concierge to help with errands that we might not have time to complete. As WCBS TV reports, "Time is so precious, and this is a way to buy time," (Cole, 2006) Similarly, personal shoppers are available to provide advice on your fashion style and to help you buy clothes (reducing the costs associated with the uncertainty of not having the good taste of buying fashionable clothes). 
A good example of converting pareto loss into revenue is the Hong Kong International Airport. The airport provides at a price, a shuttle service to transfer passengers to their gates. Passengers can choose to walk to the gates, but those who find this tiresome can opt for the buggy ride. Without this service, the walk to the gate is a pareto loss; the firm does not benefit from the walk and neither does the passenger. By providing such a service, the firm can convert pareto loss into revenue (the service provision is outsourced to a company that would presumably contribute part of its revenue to the airport). In essence, the firm has created revenue without incurring any costs, while passengers, who are not compelled to take the ride, now have a choice. Those for whom the walk is an outlay that is higher than the price of the buggy ride will certainly opt for the service. Others will walk. Converting pareto loss into a service that is chargeable provides the customer with choice.

One of the reasons why technology has been a key driver in the servitisation of the economy is because it allows more pareto losses to be converted to revenue-generating service businesses. This in turn, raises productivity levels across the board and as economists like to observe, increases consumption that would further stimulate the economy. Buyers' needs today are more complex, with a greater demand on time. Yet, the key driver isn't merely technology, but our need for more time, greater convenience and less risk.

Firms could convert pareto loss as part of service delivery even without having to charge for it e.g. reducing queues for a service (pareto loss of waiting), or providing a tracking service for courier services (pareto loss of uncertainty and loss of control). The result is increased customer satisfaction.

\section{CONCLUSION}

The explosion of pricing strategies of recent times has also been very much technology-led. Channels of purchase have increased tremendously over the past 20 years with more ways than ever to sell and deliver services. From the selling perspective, supermarkets can now sell insurance and broadband services and the mobile phone can now be a channel to sell news, music and books. From the delivery perspective, technology is now able to bring healthcare and education to the home, and banking to the beach via your laptop. With the proliferation of sales and delivery channels, service entrepreneurs and innovators are able to discover ways and means to uncover latent need for convenience and time, and meet them in innovative ways.

Consequently, buyers can now purchase through a channel that is most conducive for them, i.e. the channel that gives them the greatest value. Since the expense in purchasing a product is both the price of the product as well as the cost of acquiring it, different pareto losses exist for different channels. Converting such pareto losses would give rise to many permutations in terms of pricing. With markets now being divided into finer segments, leading to the term microsegmentation, it is now possible to price for each of these micro-segments and therefore allow firms to refine their revenue management strategies. With $3^{\text {rd }}$ generation mobile telephony, TV on the web, music on the move, convergence of mobile and internet as well as other technologies, pricing and revenue 
management strategies have to be clever, creative and innovative (Jonason, 2004). Firms that are any less dynamic run the risk of being left behind.

\section{REFERENCE}

Cole, K.(2006) 'Personal concierges becoming a new trend', WCBS.TV, Sep 26, 2006 7:51 pm US/Eastern

Jonason, A. and Holma, B. (2004) 'Innovative pricing: a case of pricing for profits on the mobile internet', International Journal of Information Technology and Management, 3, 1, 105-115

Kimes, S. E. (1989) Yield Management: A Tool for Capacity Constrained Service Firms, Journal Of Operations Mgmt, 8, 348-363

Lovelock, C., and Wirtz, J. (2003), Services Marketing: People, Technology, Strategy, 5th edition, Prentice Hall, USA.

Moon, Y.(2004), 'IKEA invades America. Harvard Business School Case Study', Case no. 5-504-094

Ng, Irene C. L. (2006), "Differentiation, Self-Selection and Revenue

Management", Journal of Revenue and Pricing Management, 5,1, 2-9 (2008), The Pricing and Revenue Management of Services, Advances in Business and Management Studies, Routledge, London. 
Irene C L Ng (2007), "Service innovation: Converting Pareto Loss into Revenue," Journal of Revenue \& Pricing Management, forthcoming

Figure 1: Evaluation of Net Value

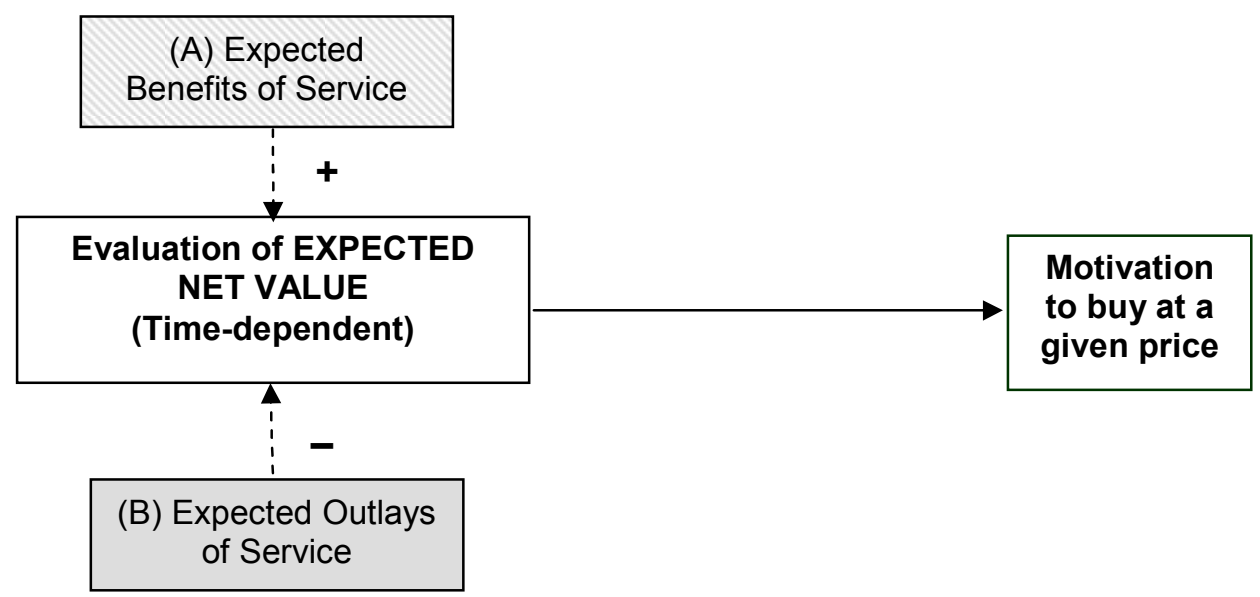


Irene C L Ng (2007), "Service innovation: Converting Pareto Loss into Revenue," Journal of Revenue \& Pricing Management, forthcoming

Figure 2: The difference between the Traditional Understanding and Revised understanding of Value

Traditional Understanding

Willingness to Pay

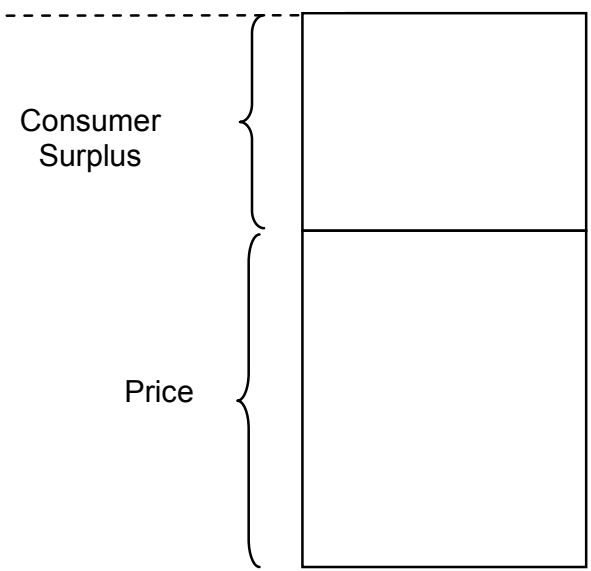

Revised Understanding

Willingness to Outlay

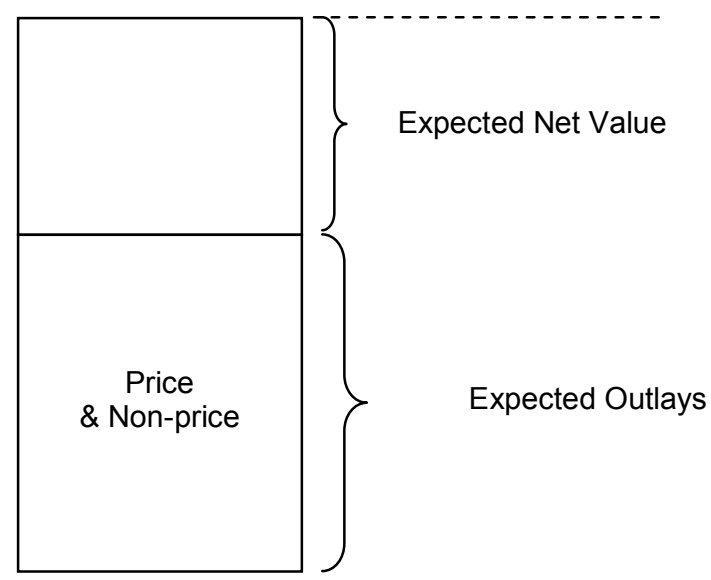


Irene C L Ng (2007), "Service innovation: Converting Pareto Loss into Revenue," Journal of Revenue \& Pricing Management, forthcoming

Figure 3: Options for Higher Revenue

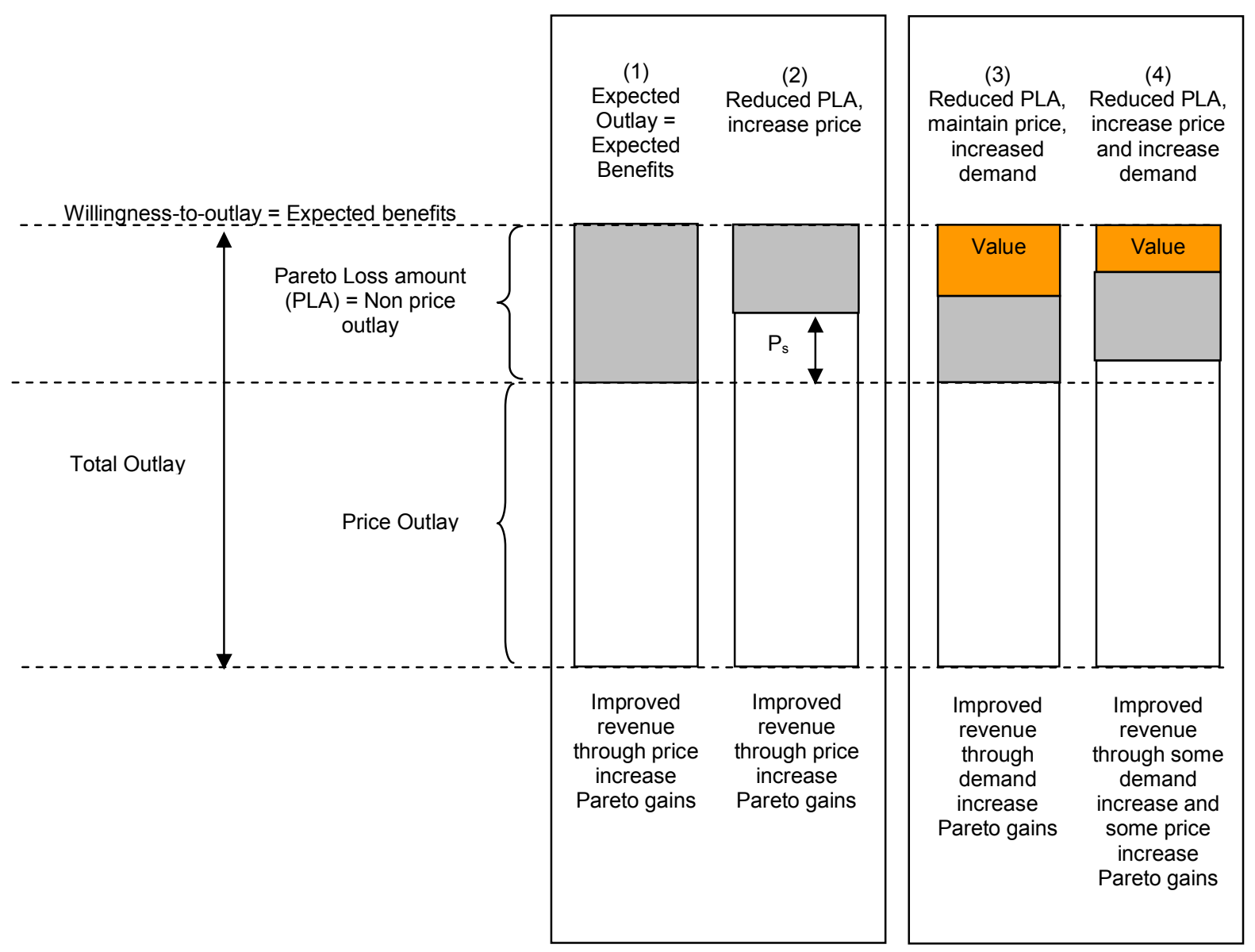

